\title{
Analysis of Mass Transfer Resistance for Adsorption of Phosphate onto Industrial Waste Materials in Plug-flow column
}

\author{
Mohd Hairul Khamidun ${ }^{1,}$, Mohammad Ashraf Abdul Rahman ${ }^{2}$ \\ ${ }^{1}$ Faculty of Civil and Environmental Engineering Universiti Tun Hussein Onn Malaysia, Batu Pahat, \\ Johor, Malaysia \\ ${ }^{2}$ Faculty of Engineering Technology, Universiti Tun Hussein Onn Malaysia, Batu Pahat, Johor, \\ Malaysia
}

\begin{abstract}
The understanding resistance of mass transfer for adsorption of phosphate $\left(\mathrm{PO}_{4}{ }^{3-}\right)$ onto industrial waste such as clay brick and ceramic as an adsorbent is important to verify. This study presented the removal of $\mathrm{PO}_{4}{ }^{3-}$ from a synthetic solution by adsorbing onto the clay brick and ceramic wastes in a plug flow column (PFC). The experimental results showed that increasing the flow rate was decreases the breakthrough time. The mass transfer factor (MTF) models were used to study the behaviours of breakthrough curve and to determine the resistance of mass transfer. The MTF models verified that the resistance of mass transfer could be dependent on porous diffusion until the percentage of outflow reaches $72 \%$ for clay brick waste and $86 \%$ for ceramic waste, even though film mass transfer can play a minor role in controlling the movement of $\mathrm{PO}_{4}{ }^{3-}$ from the bulk water to film zone. The results of MTF models coefficient could be indicated to increase the capacity of clay brick and ceramic wastes to adsorb $\mathrm{PO}_{4}{ }^{3-}$ from synthetic solution, it needs to develop the porosity of these adsorbents by either physical or chemical modification.
\end{abstract}

\section{Introduction}

Adsorption is the accumulation of a substance in solution with a suitable interface. The solute that accumulates or adsorbs at the interface is called an adsorbate; the solid that is adsorbedly the solute is called the adsorbent. The adsorbate is said to be adsorbed onto the adsorbent when it is attached at the active sites of the adsorbent surface, and it is said to be desorbed when it is released from the adsorbent into solution. The mechanisms of adsorption consist of three successive steps in the transfer of solutes onto adsorbents in liquid, such that: (1) external mass transfer is the mechanism to transport an adsorbate from the bulk liquid to film zone exterior the grain immediately connecting the pores, (2) internal mass transfer is mechanism to diffuse an adsorbate from the film zone towards acceptor sites of the adsorbent, and (3) fixation is mechanism to attach the adsorbate onto acceptor

* Corresponding author: mhairulk@gmail.com 
sites of the adsorbent interior the grain [1]. The adsorption process is one of the purification technologies and can be utilized to remove pollutants from the water. This method requires simple operation and design, and draws up a small amount of sludge [2].

Nowadays, many researchers have been studied the use of waste materials as a low cost adsorbent such cockle shell, fish scale, waste coal, solid biomass waste, food waste, newspaper waste and coffee industrial waste to remove pollutants from waters [3-7]. In the previous studies, the adsorption of $\mathrm{PO}_{4}{ }^{3-}$ from synthetic solution onto used brick as reported by Jia et al., [8], can achieve $0.90,0.97,1.09$ and $1.29 \mathrm{mg} \mathrm{P} \mathrm{g}^{-1}$ of adsorption capacity for concentration of $5,10,25$ and $50 \mathrm{mg} \mathrm{L}^{-1}$, respectively. The use of ceramic waste for the removal of $\mathrm{PO}_{4}{ }^{3-}$ from phosphorus solution to having approximately $250 \mu \mathrm{g} \mathrm{g}^{-1}$ when feeding with an initial concentration of $2000 \mu \mathrm{g} \mathrm{L}^{-1}$ [9]. Even if many adsorption models have been used to investigate the ability of using certain adsorbents to improve the adsorption performance, the use of the empirical models for scrutinizing the mass transfer factors of adsorption of $\mathrm{PO}_{4}{ }^{3-}$ onto clay brick and ceramic wastes from synthetic solution is still not fully understood. The objective of this study is to verify application of the modified mass transfer factor models and determine the variations of global mass transfer, external mass transfer and internal mass transfer coefficients for the adsorption of $\mathrm{PO}_{4}{ }^{3-}$ onto clay brick and ceramic wastes from synthetic solution in PFC.

\section{Materials and methods}

\subsection{Preparation of adsorbents}

Two types of industrial waste were used in this study as adsorbent i.e. clay brick and ceramic wastes. The clay brick waste was collected from a Materials Engineering Research Laboratory, Universiti Teknologi Malaysia. The ceramic waste was obtained from ceramic factory in Ayer Hitam, Johor state, Malaysia. All these adsorbents were crushed and passed through a sieve fraction of $1.18 \mathrm{~mm}$ and retained $0.85 \mathrm{~mm}$ mesh; thus the mean size of adsorbents was around $1.02 \mathrm{~mm}$. Approximately $2 \mathrm{~kg}$ of these adsorbents were washed with distilled water and dried at $103^{\circ} \mathrm{C}$ for $24 \mathrm{~h}$ in an oven. The dried adsorbents were used as adsorbent for the adsorption of $\mathrm{PO}_{4}{ }^{3-}$ from synthetic solution in PFC. Surface morphology of the raw adsorbents was then characterised using a scanning electron microscope (SEM, Zeiss Supra 35 V). The Fourier Transform Infrared (FTIR) Spectroscopy (Perkin-Elmer Spectrum One FTIR Spectrometer) analyses was performed in the range $600-4000 \mathrm{~cm}^{-1}$ to investigate the surface functional groups at the surface of the adsorbents.

\subsection{Preparation of synthetic solution}

Synthetic solutions with concentration of $100 \mathrm{mg} \mathrm{L}^{-1}$ of $\mathrm{PO}_{4}{ }^{3-}$ were prepared by dissolving a $0.4394 \mathrm{~g}$ of $\mathrm{KH}_{2} \mathrm{PO}_{4}$ (analytic grade), respectively, into $1 \mathrm{~L}$ of deionised water in a volumetric flask. The synthetic solution was successively diluted with deionised water to obtain the predetermined concentration of $\mathrm{PO}_{4}{ }^{3-}$. The $\mathrm{pH}$ of the synthetic solutions was set up at 6.5 for all the experiments.

\subsection{Plug-flow column reactor}

The mass transfer resistance mechanism and hydrodynamics breakthrough curve for $\mathrm{PO}_{4}{ }^{3-}$ were determined through continuous feeding of synthetic solution into PFC. A lab-scale PFC was set up, which consisted of a peristaltic pump to control the flow rate and columns 
filled with adsorbents (see Fig. 1). Samples were collected at the influent tank and the outlet of the columns before analyzing the concentration of $\mathrm{PO}_{4}{ }^{3-}$. The bed height of adsorbent filled in the column is $65 \mathrm{~cm}$ and the flow rate are $1.6,2.8$ and $3.9 \mathrm{~mL} \mathrm{~min}^{-1}$.

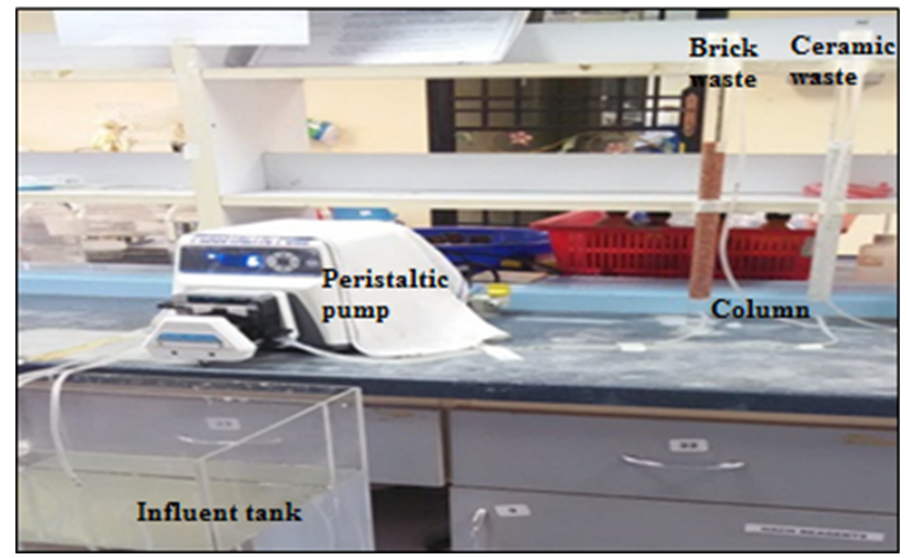

Fig. 1. Laboratory scale plug-flow column system

\subsection{Mass transfer factor models}

The mass transfer factors such as global, external and internal mass transfer can be determined by using empirical models developed by Fulazzaky [1, 10]. The modified mass transfer factor models were developed to allow the integration of knowledge concerning the considered phenomena of global, external and internal mass transfer. The use of the modified mass transfer models is able to determine the resistance of mass transfer for the adsorption of $\mathrm{PO}_{4}{ }^{3-}$ present in water onto adsorbents in PFC. The models are expressed in Equation (1) as follows

$$
\ln \left(\frac{C_{i}}{C_{e}}\right)=\left[k_{L} a\right]_{g} \times e^{-\beta \times \ln (q)} \times t
$$

where $C_{i}$ is the $\mathrm{PO}_{4}{ }^{3-}$ concentration at influent the column $\left(\mathrm{mg} \mathrm{L}^{-1}\right), C_{e}$ is the concentration of $\mathrm{PO}_{4}{ }^{3-}$ effluent at the column (mg L$\left.{ }^{-1}\right),\left[k_{\mathrm{L}} a\right]_{\mathrm{g}}$ is the global mass transfer factor $\left(\mathrm{h}^{-1}\right), \beta$ is the absorbent - adsorbent affinity parameter $\left(\mathrm{g} \mathrm{h} \mathrm{mg}^{-1}\right) ; q$ is the cumulative quantity of the solute to be adsorbed onto adsorbents $\left(\mathrm{mg} \mathrm{g}^{-1}\right)$; and $t$ is the accumulated time $(h)$

The mathematical deduction of equation (1) can be simplified as:

$$
\begin{gathered}
\ln (q)=\alpha \ln (t)+\operatorname{Bln}(q)=m \ln (t)+B \\
\text { where, } \quad \alpha=1 / \beta
\end{gathered}
$$

and $B$ is the intercept of the plot $\ln (q)$ versus $\ln (t)$ :

$$
B=\frac{\ln \left(\left[k_{L} a\right]_{g}\right)-\ln \left\{\ln \left(\frac{C_{i}}{C_{e}}\right)\right\}}{\beta}
$$


The value of $\left[k_{\mathrm{L}} a\right]_{\mathrm{g}}$ can be determined using Equation (1) since the index $B$ and the parameter $\beta$ has been verified on a straight line of a plot of $\ln (q)$ versus $\ln (t)$. Equation (5) permits the computation of the film mass transfer factor $\left(\mathrm{h}^{-1}\right)\left[\mathrm{k}_{\mathrm{L}} \mathrm{a}\right]_{\mathrm{f}}$, and Equation $(6)$ can be used to determine the porous diffusion factor $\left(\mathrm{h}^{-1}\right)\left[k_{\mathrm{L}} a\right]_{\mathrm{d}}$.

$$
\begin{aligned}
{\left[k_{L} a\right]_{f} } & =\left[k_{L} a\right]_{g} \times e^{-\beta \times \ln (q)} \\
{\left[k_{L} a\right]_{d} } & =\left[k_{L} a\right]_{g}-\left[k_{L} a\right]_{f}
\end{aligned}
$$

\section{Results and discussions}

\subsection{Characteristics of adsorbents}

Fig. 2 shows the FTIR spectra of unmodified clay brick (Fig.2A) and ceramic (Fig.2B) wastes. FTIR spectra of the clay brick waste exhibited bands at 1750, 16201042,747 and $632 \mathrm{~cm}^{-1}$ (see Fig. 2A). The bands in range $1620-1750 \mathrm{~cm}^{-1}$ are attributed to H-O-H bending [11]. The asymmetric stretch of Al-O are observed at bands $1042 \mathrm{~cm}^{-1}$ [12]. The bands at 747 and $632 \mathrm{~cm}^{-1}$ indicated the presence of mineral quartz and $\mathrm{Si}-\mathrm{O}-\mathrm{Al}$ bond, respectively [13]. Fig. 2(B) is FTIR spectrums of the ceramic waste. The analysis of spectrums indicated sharp peak at $1580 \mathrm{~cm}^{-1}$ is due to scattering from atmospheric oxygen [14]. The peaks in the region of $1600-1800 \mathrm{~cm}^{-1}$ are associated with the acetate groups [15]. The broad peak around $1100 \mathrm{~cm}^{-1}$ is characteristics of asymmetrical $\mathrm{Si}-\mathrm{O}-\mathrm{Si}$ stretching [16].
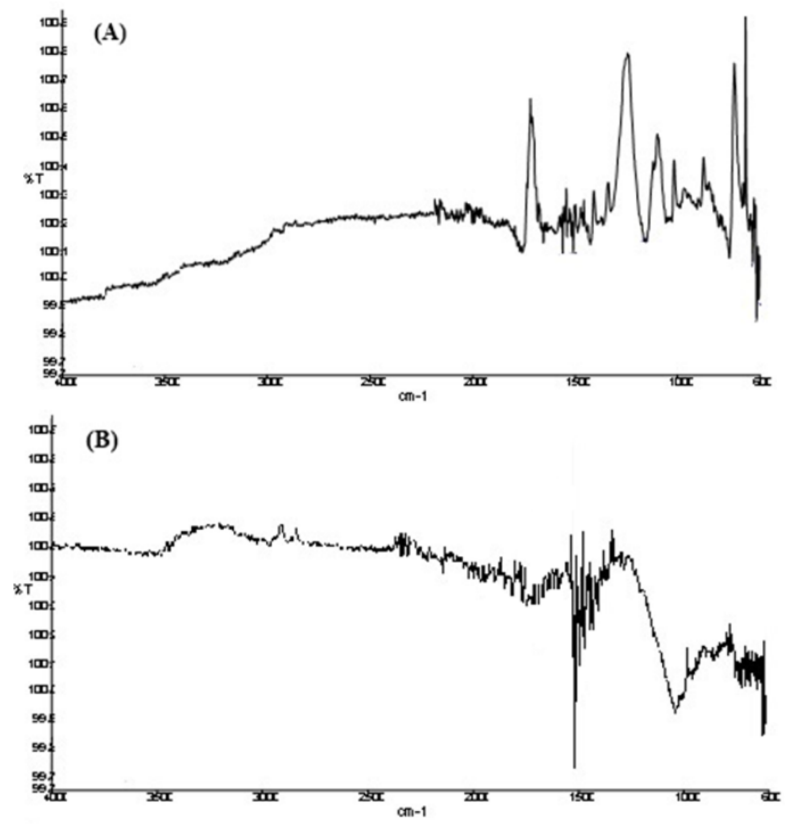

Fig. 2. FTIR spectra of (A) brick waste and (B) ceramic waste

The surface morphology of brick and ceramic wastes was investigated by SEM analysis and the SEM images are shown in Fig. 3. Fig. 3(A) shows that the SEM image of 1000 times magnification are drusy texture with micro porosity of the brick waste surface. 
Fig. 3(B), the microscopic image of ceramic waste, shows quite smooth and wavy ripple morphology on the surface.
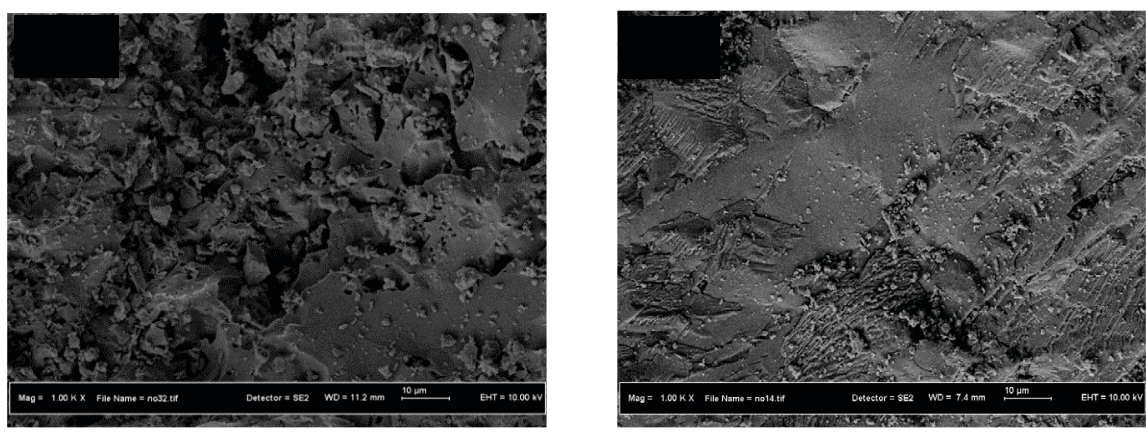

Fig. 3. SEM photomicrograph of (A) clay brick waste and (B) ceramic waste at overview 1000 times magnification

\subsection{Plug-flow column study}

Fig. 4 shows the variations of $C_{e} / C_{i}$ versus $t$ for the adsorption of $\mathrm{PO}_{4}{ }^{3-}$ onto clay brick waste (Fig. 4(A)) and ceramic waste (Fig.4(B)) from synthetic solution in continuous PFC. The figure shows that the use of brick waste to adsorb $\mathrm{PO}_{4}{ }^{3-}$ could be more efficient than that the use of ceramic waste. As shown in Fig. 4, the adsorption efficiency decreases with increasing the flow rate. The decrease in adsorption efficiency due to fact that the increased flow rate may decrease the residence time of $\mathrm{PO}_{4}{ }^{3-}$ to attach onto the surface of adsorbents. The higher adsorption of $\mathrm{PO}_{4}{ }^{3-}$ onto clay brick waste due to $\mathrm{H}-\mathrm{O}-\mathrm{H}, \mathrm{Al}-\mathrm{O}$ and $\mathrm{Si}-\mathrm{O}-\mathrm{Al}$ functional groups on the surface could ion exchange and precipitate with $\mathrm{PO}_{4}{ }^{3-}$ [17], [18]. The analyses of mass transfer factor models were performed for the adsorption of $\mathrm{PO}_{4}{ }^{3-}$ in

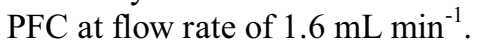
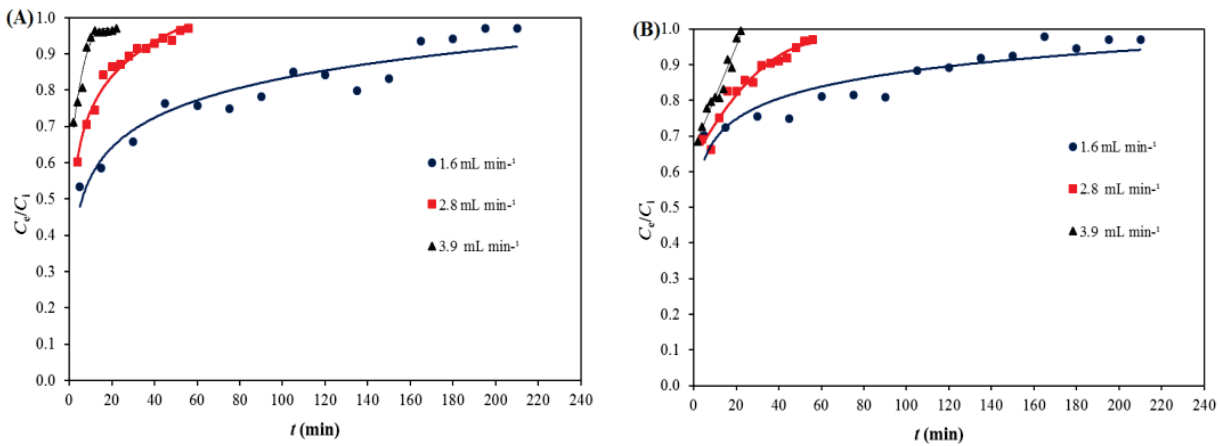

Fig. 4. Breakthrough curves for the adsorption of $\mathrm{PO}_{4}{ }^{3-}$ from synthetic solution onto (A) brick and (B) ceramic wastes.

\subsection{Application of Mass Transfer Factor Models}

A linear regression analysis of using the experimental data shows a good correlation for all the curves of plotting $\ln (q)$ versus $\ln (t)$ in Equation (2) for flow rate of $1.6 \mathrm{~mL} \min ^{-1}\left(R^{2}>0.976\right.$; see Table 1$)$, meaning that the use of the parameters $B$ and $\beta$ can 
be used to determine the mass transfer potential and adsorbate-adsorbent affinity for the adsorption of $\mathrm{PO}_{4}{ }^{3-}$ from synthetic solution onto clay brick and ceramic wastes. The experimental data validation (Table 1) shows that the value of $B$ and $\beta$ for clay brick waste is higher than ceramic waste could be due to a high $\mathrm{PO}_{4}{ }^{3-}$ concentration in the stagnant film on the water side of the interface, affecting the value of driving force reduces because of the difference in $\mathrm{PO}_{4}{ }^{3-}$ concentration between the bulk water and film zone lowers [19].

Table 1. Results of determining the values of $\beta$ and $B$ for clay brick and ceramic wastes in plug-flow column

\begin{tabular}{|c|c|c|c|}
\hline Adsorbent & $\boldsymbol{\beta}(\mathbf{g ~ h} / \mathbf{m g})$ & $\boldsymbol{B} \mathbf{( m g} / \mathbf{g})$ & $\boldsymbol{R}^{\mathbf{2}}$ \\
\hline Clay brick waste & 1.3358 & -9.913 & 0.988 \\
\hline Ceramic waste & 1.2758 & -10.38 & 0.978 \\
\hline
\end{tabular}

Using Equation (4) permits us to determine the variations of $[k \mathrm{~L} a] \mathrm{g}$ pursuant to the percentage of outflow if the parameters $B$ and $\beta$ were verified. Fig. 5 shows the variations of $[k \mathrm{La}] \mathrm{g}$ decreased progressively from a high to low mass transfer potential with increasing of the percentage of outflow. The variation of $[\mathrm{kLa}] \mathrm{g}$ value for clay brick waste packed-bed column is quite high when comparing to ceramic waste packed-bed column as shown in Fig. 5. This could be due to high adsorbateadsorbent affinity of clay brick waste to attract $\mathrm{PO}_{4}{ }^{3-}$ from bulk water when passing through packed-bed column [20].

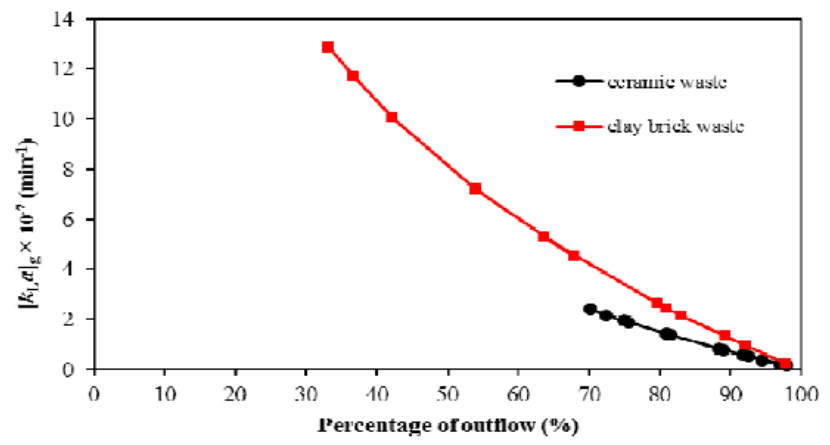

Fig. 5. Variations of $\left[k_{\mathrm{L}} a\right]_{\mathrm{g}}$ pursuant to the percentage of outflow for clay brick waste (red line) and ceramic waste (black line) in plug-flow column

As can be seen in Fig. 6 the variations of $\left[k_{\mathrm{L}} a\right]_{\mathrm{f}}$ rapidly decrease, counterbalanced by the variations of $\left[k_{\mathrm{L}} a\right]_{\mathrm{d}}$ rapidly increase when the percentages of outflow are still less than $63 \%$ for clay brick waste and $76 \%$ for ceramic waste. After passing a $63 \%$ and $76 \%$ of outflow for clay brick waste and ceramic waste, respectively; the variations of $\left[k_{\mathrm{L}} a\right]_{\mathrm{f}}$ slowly decrease but the variations of $\left[k_{\mathrm{L}} a\right]_{\mathrm{d}}$ slowly increase until percentage of outflow reach at approximately $72 \%$ and $86 \%$ for clay brick waste and ceramic waste, respectively. Based on the variations of $\left[k_{\mathrm{L}} a\right]_{\mathrm{f}}$ and $\left[k_{\mathrm{L}} a\right]_{\mathrm{d}}$, it would be concluded that the resistance of mass transfer for the adsorption of $\mathrm{PO}_{4}{ }^{3-}$ onto clay brick and ceramics wastes is dependent on porous diffusion before a breakthrough occurs and then to continue until it reaches at approximately $63 \%$ and $76 \%$ of the outflow for clay brick waste and ceramic waste, respectively. In spite of the transport of $\mathrm{PO}_{4}{ }^{3-}$ from the bulk water to film zone and then to acceptor sites within the pores is very slow, the resistance of mass transfer 
could be dependent on both film mass transfer and porous diffusion when the percentages of outflow are greater than $72 \%$ and $86 \%$ for clay brick waste and ceramic waste, respectively.
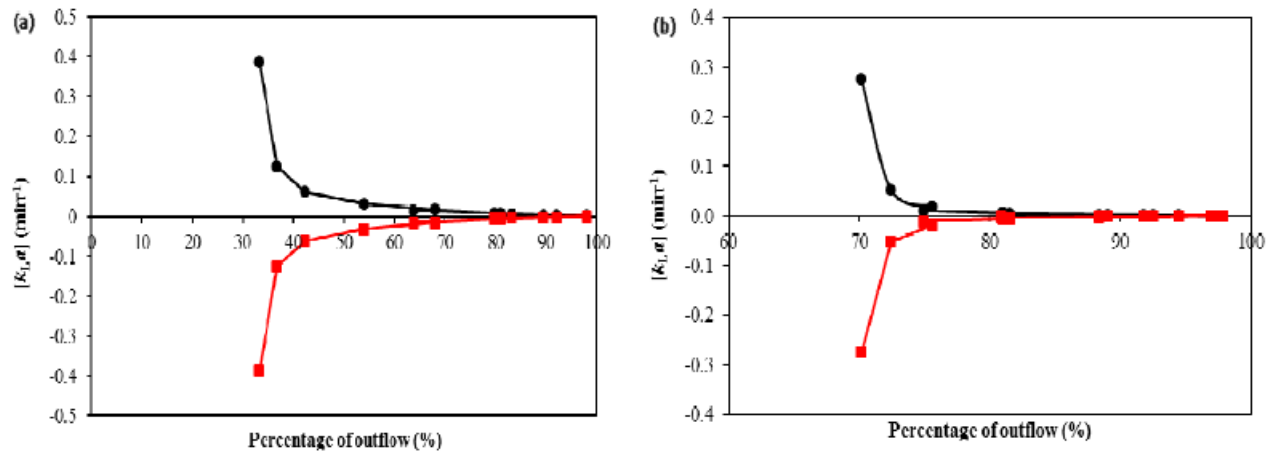

Fig. 6. Variations of $\left[k_{\mathrm{L}} a\right]_{\mathrm{f}}$ (black line) and $[k \mathrm{~L} a] \mathrm{d}$ (red line) pursuant to the percentage of outflow for (a) clay brick waste and (b) ceramic waste in plug-flow column.

\section{Conclusion}

As a conclusion, the adsorption of $\mathrm{PO}_{4}{ }^{3-}$ onto clay brick and ceramic wastes might allow precipitation occurred by a chemisorption process while the van der Waals forces would be quite difficult due to the porosity of the adsorbents very small (confirmed by SEM image). Therefore, in order to increase the capacity of these adsorbents to adsorb $\mathrm{PO}_{4}{ }^{3-}$ from waters, it needs to develop the porosity of clay brick and ceramic wastes by either physical or chemical modification. In addition, the resistance of mass transfer for the adsorptions of $\mathrm{PO}_{4}{ }^{3-}$ onto clay brick and ceramic wastes from synthetic solution processing in a PFC was verified to contribute to the development of such porous materials for improving separation performance.

The author thank the Universiti Tun Hussien Onn Malaysia, for short term grant under grant no Vot U635.

\section{References}

[1] M. A. Fulazzaky, Determining the resistance of mass transfer for adsorption of the surfactants onto granular activated carbons from hydrodynamic column, Chem. Eng. J., 166(3), 832-840, (Feb.,2011)

[2] R. Boopathy, S. Karthikeyan, A. B. Mandal, and G. Sekaran, Adsorption of ammonium ion by coconut shell-activated carbon from aqueous solution: kinetic, isotherm, and thermodynamic studies., Environ. Sci. Pollut. Res. Int., 20(1), 533-542, (Jan, 2013)

[3] B. G. Tsyntsarski, B. N. Petrova, T. K. Budinova, N. V Petrov, and D. K. Teodosiev, Removal of phenol from contaminated water by activated carbon produced from waste coal material, Bulg. Chem. Commun., 46(2), 353-361, (2014)

[4] M. Shanmugaprakash, V. Sivakumar, and M. Manimaran, Batch and Dynamics Modeling of the Biosorption of Cr (VI) from Aqueous Solutions by Solid Biomass Waste from the Biodiesel Production, Environ. Prog. Sustain. Energy, 33(2), 342-352, (2014) 
[5] A. Shehzad, M. J. K. Bashir, S. Sethupathi, and J.-W. Lim, An overview of heavily polluted landfill leachate treatment using food waste as an alternative and renewable source of activated carbon, Process Saf. Environ. Prot., 98, 309-318, (2015)

[6] M. H. Dehghani, D. Sanaei, I. Ali, and A. Bhatnagar, Removal of chromium(VI) from aqueous solution using treated waste newspaper as a low-cost adsorbent: Kinetic modeling and isotherm studies, J. Mol. Liq., 215, 671-679, (2016)

[7] N. Zayadi and N. Othman, Characterization and Optimization of Heavy Metals Biosorption by Fish Scales, Adv. Mater. Res., 795, 260-265, (2013)

[8] C. Jia, Y. Dai, J. Chang, C. Wu, Z. Wu, and W. Liang, Adsorption characteristics of used brick for phosphorus removal from phosphate solution, Desalin. Water Treat., 51, 5886-5891, (2013)

[9] J. Wang, Y. Zhang, C. Feng, H. Wang, and L. Wang, Adsorption Capacity Comparison among Three Filter Media for Phosphorus, 2010 4th Int. Conf. Bioinforma. Biomed. Eng., 1-4, Jun. (2010)

[10]M. A. Fulazzaky, M. H. Khamidun, M. F. M. Din, and A. R. M. Yusoff, Adsorption of phosphate from domestic wastewater treatment plant effluent onto the laterites in a hydrodynamic column, Chem. Eng. J., 258, 10-17, (2014)

[11]M. F. Zawrah, R. A. Gado, N. Feltin, S. Ducourtieux, and L. Devoille, Recycling and utilization assessment of waste fired clay bricks ( Grog ) with granulated blast-furnace slag for geopolymer production, Process Saf. Environ. Prot., 103, 237-251, (2016)

[12]F. Kooli, L. Yan, R. Al-Faze, and A. Al-Sehimi, Removal enhancement of basic blue 41 by brick waste from an aqueous solution, Arab. J. Chem., 8(3), 333-342, (2015)

[13]J. A. Calabria, W. L. Vasconcelos, and A. R. Boccaccini, Microstructure and chemical degradation of adobe and clay bricks, Ceram. Int., 35, 665-671, (2009)

[14] T. Hirose, T. Fujino, T. Fan, and H. Endo, Effect of carbonization temperature on the structural changes of woodceramics impregnated with liquefied wood, Carbon N. Y., 40, 761-765, (2002)

[15]M. A. Gulgun, M. H. Nguyen, and W. M. Kriven, Polymerized Organic - Inorganic Synthesis of Mixed Oxides, J. Am. Ceram. Soc., 82(3), 556-560, (1999)

[16]K. Lin, W. Chang, T. Chang, C. Lee, and C. Lin, Recycling thin film transistor liquid crystal display ( TFT-LCD ) waste glass produced as glass - ceramics, J. Clean. Prod., 17(16), 1499-1503, (2009)

[17]M. A. Fulazzaky, N. A. A. Salim, N. H. Abdullah, A. R. Mohd Yusoff, and E. Paul, Precipitation of iron-hydroxy-phosphate of added ferric iron from domestic wastewater by an alternating aerobic-anoxic process, Chem. Eng. J., 253, 291-297, (2014)

[18]S. Sengupta and A. Pandit, Selective removal of phosphorus from wastewater combined with its recovery as a solid-phase fertilizer., Water Res., 45(11), 3318-3330, (2011)

[19]M. H. Khamidun and M. A. Fulazzaky, Adsorption of phosphate from synthetic solution onto the limestone in a plug - flow column, Int. J. Adv. Appl. Sci., 2(12), 713, (2015)

[20]M. H. Khamidun, M. A. Fulazzaky, M. F. Md Din, and A. R. Mohd Yusoff, Resistance of mass transfer, kinetic and isotherm study of ammonium removal by using a Hybrid Plug-Flow Column Reactor ( HPFCR ), Proceedings of the 2013 International Conference on Frontier of Energy and Environment Engineering, ICFEEE 2013, 555559 (2014) 